\title{
The use of artificial teeth in a pre-clinical fixed prosthodontics post-core undergraduate teaching program
}

James Dudley ( $\sim$ james.dudley@adelaide.edu.au )

The University of Adelaide

Research article

Keywords: Artificial teeth, Post-core, Undergraduate curriculum, Pre-clinical simulation teaching, Fixed prosthodontics

Posted Date: October 26th, 2020

DOI: https://doi.org/10.21203/rs.3.rs-78753/v1

License: (c) (i) This work is licensed under a Creative Commons Attribution 4.0 International License.

Read Full License 


\section{Abstract \\ Background}

The use of artificial teeth in pre-clinical simulation clinic teaching of post-core techniques has clear educational benefits for students and staff. This study explored the reasons for selection and direct student experiences with artificial teeth in a recently conducted pre-clinical fixed prosthodontics post-core technique teaching program.

\section{Methods}

An online anonymous survey was delivered to fourth year undergraduate dental students who had completed the fixed prosthodontics pre-clinical program seeking information on the choice of artificial or natural teeth and direct experiences. Quantitative data was summarised and qualitative data was clustered into topics.

\section{Results}

A $100 \%$ response rate was received. $36 \%$ of 70 respondents chose to use one or more artificial teeth for the post-core exercises which was predominantly driven by difficulty in sourcing appropriate natural teeth (59\%) rather than educational benefit (13\%). 45 (64\%) chose not to use artificial teeth largely due to the cost of the teeth $(49 \%)$.

\section{Conclusions}

Direct student experiences in using the artificial teeth for post-core exercises were positive. In the choice to select artificial or natural teeth for post-core exercises, teaching staff may focus on educational benefits while students focus on the practicalities of sourcing teeth, associated costs and ease of use. As the first known research of its kind, within the limitations of this study artificial teeth provided an appropriate and realistic simulation compared to extracted natural teeth and were easier to source for the post-core exercises of the pre-clinical fixed prosthodontics program. More widespread use of artificial teeth was limited by cost.

\section{Introduction}

\section{Pre-clinical teaching}

Fixed prosthodontics teaching in undergraduate dental curricula has traditionally included pre-clinical courses covering theory and practical techniques in crown preparation and post-core procedures. The importance of pre-clinical dental education has been demonstrated as a key factor in facilitating a 
smooth transition to the clinical setting. ${ }^{1}$ There is an established positive correlation of pre-clinical grades with clinical grades in operative dentistry and fixed prosthodontics. ${ }^{2}$

Dental simulation clinic teaching has established itself as a mainstay in pre-clinical teaching for students to develop practical skills. ${ }^{3}$ Simulation clinic teaching has been used extensively in both pre-clinical and end-point fixed prosthodontics teaching modalities where students typically complete a sequence of formative practical exercises culminating in a summative practical assessment. ${ }^{4}$ In some curricula, dental simulation clinic teaching has significantly replaced clinical practice.

\section{Post-core restorations}

Post-core restorations facilitate the reconstruction of endodontically treated teeth and present advantages over extraction and tooth replacement enabling patients to retain natural teeth for longer. ${ }^{5}$ In the modern era of dentistry with an ever-increasing placement of dental implants, post-core procedures may be thought of as a forgotten art, however they have an important role in restorative dentistry and prosthodontics particularly with adults retaining more teeth for longer. ${ }^{6,7}$ Typically, teeth requiring postcore restorations have minimal remaining sound tooth structure and require assessment of the volume of remaining tooth structure, location of remaining tooth structure, and adequate ferrule prior to consideration for post-core restoration. ${ }^{8}$

The normal purpose of a post is to retain the coronal restoration..$^{9,10}$ The coronal restoration may comprise a core that provides adequate coronal structure through key principles of retention and resistance form for an artificial crown ${ }^{9}$ or may be a stand-alone restoration in itself. The core can be constructed in conjunction with the post as in the case of a traditional cast post-core, or, may be constructed separately and chemically and/or mechanically retained by the post.

Historically, cast post-cores were constructed using the direct (intraoral) resin pattern then casting by means of the lost wax system. Today, there is a myriad of options, post types and materials available in the marketplace including prefabricated, cast, metallic, non-metallic, active, passive, bonded, cemented, direct and indirect varieties. ${ }^{10,11}$ Most available post-systems can be used provided certain principles are followed. ${ }^{12}$

Despite the provision of guidelines, post selection can be challenging and requires guidance at the beginner level as there are a multitude of factors that require consideration. ${ }^{13}$ Furthermore, the mechanisms of post failure should also be known and can be quite specific to the post type. ${ }^{14,15,16}$ Postcore procedures are complex and require a high level of skill. It is therefore imperative undergraduate dental students are trained accordingly.

\section{Simulation clinic teaching of post-core techniques}

Traditionally, extracted natural teeth have been sourced for pre-clinical simulation clinic teaching of fixed prosthodontics and post-core techniques. In recent years, limitations have been encountered such as 
ethical barriers, cross-infection requirements, sourcing teeth with appropriate tooth structure, and sourcing teeth with appropriate root canal anatomy. The nature of variations in natural teeth limit the standardisation, repeatability and consistency of teaching and can result in a diverse range of student experience of learning.

The benefits of using artificial teeth in simulation teaching in fixed prosthodontics include standardisation of teeth, standardisation of techniques, life-like appearance, facilitation of repeatable practical demonstrations that are directly applicable to the student's tooth, and being readily available. The known shortcomings are limitations in the anatomical simulation of natural teeth, different surface textures compared to natural teeth, and the cost involved in obtaining teeth, models and manikins.

As education philosophes and technology have evolved, the benefits of teaching alternative and modernised techniques in fixed prosthodontics have been established resulting in quality gains evidenced by students producing closer to ideal crown preparations. ${ }^{17,18}$ Dental simulation teaching has expanded beyond the traditional manikin model to encompass virtual reality technologies. ${ }^{3,19}$ Recent developments have been directed at 3D technologies associated with the creation of layered artificial teeth. ${ }^{20,21,22}$ Artificial endodontic teeth have been produced and used in endodontic pre-clinical teaching with promising initial results ${ }^{23}$ but there have not yet been any reports for post-core teaching.

\section{Study Aim}

Although extracted natural teeth provide a high-fidelity experience, the dominant challenges in using natural teeth for post-core pre-clinical fixed prosthodontics procedures have been sourcing appropriate teeth and when sourced the compromised restorative state. Research specifically focussed on undergraduate pre-clinical education in post-core techniques is scarce. More specifically there remains a dearth of evidence on the use of artificial teeth in the education of undergraduate students specifically in post-core exercises.

The aim of this study was to explore the reasons for selection and direct student experiences with artificial teeth in a recently conducted pre-clinical fixed prosthodontics post-core technique teaching program using a survey of student experience.

\section{Methods}

\section{Ethical considerations}

Ethics approval was obtained from the Human Research Ethics Committee at The University of Adelaide (H-2020-106).

\section{Context}

Fourth year undergraduate dental students undertaking the fixed prosthodontics pre-clinical program at the Adelaide Dental School, The University of Adelaide were presented with an option to source extracted 
natural teeth or purchase artificial teeth (Fig. 1) at A\$25 per tooth prior to the post-core component of the program. A total of six teeth were required for all post-core exercises. Any combination of artificial and natural teeth was permissible, all of which could be used in the same acrylic base model fitted to the manikin head. The teeth were manufactured using conventional moulding techniques, not threedimensional (3D) layering. The use of the teeth for the set exercises followed a comprehensive fixed prosthodontics didactic program and was conducted in a dental simulation clinic.

\section{Survey Development}

Two surveys were developed according to whether students used artificial teeth (Survey 1 ) or natural teeth (Survey 2) for the post-core exercises in the fixed prosthodontics pre-clinical program (Table 1). The questions were a combination of five-point Likert scale, yes/no, multiple choice, and open-ended questions and examined the choice of teeth, reasons for choice and direct experiences and observations.

Insert Table 1.

\section{Participants}

All fourth-year students were sent an email after finishing the program requesting completion of one of the two anonymous online survey links, administered using Survey Monkey (SurveyMonkey ${ }^{\mathrm{TM}}$, San Mateo, CA, USA).

\section{Data collection and analysis}

The surveys were conducted over a period of one week. All responses were anonymous. At the end of the survey period, the responses to five-point Likert scale, yes/no and multiple choice questions were summarised in Microsoft Excel software (version 2016) and presented in tabulated form. Scores of 1, 2, 3, 4, 5 were assigned to the five-point Likert scale questions reflecting the degree of agreement. Qualitative data was clustered into topics and analysed in Microsoft Excel software (version 2016) and presented in tabulated form.

\section{Results}

A $100 \%$ response rate was received. Of the 70 respondents, 25 (36\%) chose to use one or more artificial teeth for the post-core exercises in the pre-clinical program, with 17 (68\%) of these respondents choosing three or less of the possible six artificial teeth. 45 (64\%) respondents chose not to use artificial teeth, choosing to use only natural teeth.

\section{Survey 1 (Artificial Teeth)}

For the 25 respondents who used at least one artificial tooth, the reasons for choosing artificial teeth were dominated by difficulty in sourcing appropriate natural teeth (59\% of responses) compared $13 \%$ reasoning an educational benefit (Fig. 2). 
When the direct student experiences of using artificial teeth were examined with open ended questions, 'ease of use' was established as a dominant positive aspect accounting for $52 \%$ of 71 responses. The main negative aspect was 'unrealistic simulation of natural teeth' representing $50 \%$ of 64 responses.

When compared with natural teeth, $28 \%(n=7)$ found artificial teeth to have the same surface texture using a high speed bur whereas $44 \%(n=11)$ found the artificial teeth a little harder; $56 \%(n=14)$ found the canals were a little easier to locate; and $36 \%(n=9)$ found the same ease of deviating or perforating from the obturated canal compared with natural teeth.

Two of the 25 respondents reported perforating the artificial teeth.

\section{Survey 2 (Natural Teeth)}

Of the 45 respondents who chose only natural teeth for post-core exercises, $49 \%$ of 79 responses reported the selection was due to 'artificial teeth cost too much' (Fig. 3). If given the choice again, $23(51 \%)$ of the respondents would choose artificial teeth at the same cost.

For the 45 respondents who did not use any artificial teeth, if they were to use artificial teeth in the future the perceived benefits were dominated by 'ease of use' ( $45 \%$ of 118 responses) (Fig. 4) whereas the perceived negative aspects focussed on 'unrealistic simulation of natural teeth' (48\%) and 'cost ' (27\% of 118 responses) (Fig. 5).

The average cost that the same respondents were willing to pay in the future for artificial teeth was A $\$ 6.43$ per tooth with $73 \%$ of respondents willing to pay A\$6 or less per tooth $(n=45)$.

\section{Discussion}

\section{Direct findings}

The study found a range of reasons for the selection of artificial teeth for post-core pre-clinical exercises but was predominantly explained by difficulty in sourcing appropriate natural teeth. Beyond ethical considerations, obtaining appropriate tooth types (single rooted, multiple rooted) with appropriate root anatomy, in a restorable state, in large numbers, and for large numbers of students is a challenge that obtaining artificial teeth from a dispensing machine overcomes.

For the $36 \%$ of respondents who used artificial teeth, cost was not reported as a major drawback. The dominant direct beneficial experiences of students who used artificial teeth was the ease of use and the main negative aspect was unrealistic simulation of natural teeth, which are somewhat contradictory. Further investigation is required but could in theory be reasoned by the pristine unrestored nature of the artificial teeth compared with the frequently heavily restored, diseased or broken-down natural teeth. Artificial teeth were judged by respondents who used the teeth as similar to natural teeth in surface texture and ease of deviating from the obturated canal but slightly easier to locate the canal which reinforces the appropriateness of using artificial teeth in post-core pre-clinical programs. 
Contrastingly, it was apparent that cost served as an initial barrier to choosing artificial teeth over sourcing natural teeth as demonstrated by the $64 \%$ of respondents who chose not to use any artificial

teeth. Students already have significant educational expenses and when posed with a decision to outlay further, they predominantly chose to source natural teeth at their own individual time and effort expense. Students have choices, their opinions can be influenced by a variety of factors, and in practical terms it may have been a relatively simple decision of cost outweighing convenience.

The $64 \%$ of respondents who did not use artificial teeth perceived future potential benefits as ease of use but were concerned with the potential unrealistic simulation of natural teeth more than cost. Surprisingly, educational benefit did not feature highly in the responses. Students may have a different perspective to that of teaching staff, focussing more on the practicalities of sourcing teeth, associated costs and ease of use rather than educational benefit. The ability to use standardised simulation teaching resources has clear educational benefits, where a consistent educational experience can be provided and repeated for all students in the class at different points in time. Students may perceive cost as a barrier to gaining educational benefit.

\section{Comparative research}

There has been no known previous research in this specific field of the use of artificial teeth in post-core teaching of undergraduate students, as such direct comparisons are limited. Overarching surveys of curriculum structure, techniques taught, and materials used in undergraduate prosthodontics courses (that include fixed prosthodontic components) have been conducted at various points in time $24,25,26,27$ and have fuelled recommendations and publication of curriculum guidelines. ${ }^{28}$ Surveys of student experiences have been performed in the broader prosthodontics educational context including self-report of confidence in undergraduate removable prosthodontic education ${ }^{29}$ and effectiveness of preclinical courses in preparing students for patient treatment. ${ }^{30}$ More specific research has focussed on student experiences in fixed prosthodontics such as using 3D scanner technologies to more objectively assess student crown preparations ${ }^{31}$ teaching different crown preparation techniques ${ }^{32}$ and evaluating the effectiveness of different teaching methodologies using digital and real time technologies. ${ }^{18}$ Each has proposed educational benefits.

An underpinning principle of successful pre-clinical fixed prosthodontics education is that simulation teeth should have an accurate and realistic representation of natural teeth while ideally circumventing the educationally limiting complexities in post-core technique teaching such as fine, blocked and curved canals. In the present study, artificial teeth were predominantly reported to have the same or a little harder surface texture as natural teeth when using a high speed bur which tends to agree with a comparative study where the majority $(71.1 \%)$ of the students thought there was not much difference in the tactile sense between natural teeth and the typodont teeth, notwithstanding the unknown brand of tooth used in the comparative study. ${ }^{33}$ When coupled with the present study's finding that it was a little easier to locate the canals on artificial teeth than natural teeth, the initial use of artificial teeth for post-core teaching 
appears to suggest a beneficial educational experience for students especially at the commencement level.

The limitations of using natural teeth for endodontic pre-clinical teaching have previously been recognised ${ }^{34}$ and their use may not represent a completely beneficial educational experience at the beginner level considering the intricacies of the root canal system. The use of artificial teeth for endodontic pre-clinical procedures has been associated with promising initial results using traditionally mould-formed teeth ${ }^{23}$ and 3D printed teeth ${ }^{35}$ but the tooth hardness has been criticised. Clearly, further research and development is required in this area.

\section{Artificial tooth development}

The development of artificial teeth for use in simulation teaching has rapidly advanced in recent years. 3D printing of teeth with different layers may present reduced cost and manufacturing time benefits and their use has been found to have a positive impact on the educational experience of students performing post preparations. ${ }^{21}$ However, the hardness of the teeth has received initial criticism ${ }^{21}$ with new materials proposed to address this issue. The hardness of 3D printed teeth has not been widely analysed specifically in post-core procedures and requires further refinement.

This was the first time artificial teeth had been included as an option in the post-core component of this study's pre-clinical program, therefore no preceding student experiences were available. The manufacturing company of the artificial teeth proposed user benefits of a natural root form tooth model with anatomical pulp cavity, radiographic imaging ability, and a difference in cutting feel between the enamel and the dentin material similar to natural teeth. ${ }^{36}$ The range of teeth is at present limited and being further developed.

\section{Clinical applications and the importance of post-core education}

Extensive clinical research has been published in the field of post-core materials and techniques including reviews of the founding principles ${ }^{8}$ and systematic reviews and meta-analyses that claim high success rates in anterior and posterior teeth. ${ }^{37}$ The cumulative survival rate of post-core restorations has been reported at $86 \%$ at 10 years ${ }^{38}$ with summary rates of root fracture of less than $2 \%{ }^{39}$ but dependent on the post material and modulus of elasticity. However, the path to success is multi-factorial and especially influenced by the selected post system. ${ }^{37,40}$

Clinical practice has been reported as the key to competence and undergraduates' perceived competence in prosthodontics has been directly related to the number of treatments performed. ${ }^{41}$ Pre-clinical education, as the precursor to clinical experience, is an essential component in the undergraduate dental curriculum. In this context of performing a complex procedure usually due to the substantial loss of coronal tooth structure, and with a myriad of post systems available in the marketplace, it is critical graduating dental students have a grounding in the mainstream post-core systems. The teaching of post- 
core exercises still represents a key component of the undergraduate fixed prosthodontics programs in training dental students to be competent dentists.

\section{Limitations}

The $100 \%$ response rate was an excellent result and has been reported in other studies of similar type ${ }^{29}$ and location ${ }^{42}$ involving student participants. Although representative of this particular student cohort, the study was conducted at a single dental school and the results may not be generalisable to students in other programs. The responses were taken at a single point in time after the completion of the pre-clinical program and gathered retrospective data. The demographic of gender distribution was not investigated and the study included a relatively small number of students who chose to use a relatively small number of artificial teeth. The results have a distinct educational focus and cannot be applied clinically. Nevertheless, in the context of limited previous research in this area, the present study's findings are encouraging and should serve as a sound precedent for further research.

\section{Recommendations}

Based on the current available research, the author's proposal for future teaching of post-core techniques in a fixed prosthodontics pre-clinical program is to use artificial teeth for initial training leveraging the benefits of simplicity and standardisation to build initial skills. When initial skills have been formed, proceed to further pre-clinical training on extracted natural teeth utilising their realistic properties of surface texture and the unique features frequently encountered in natural teeth before progressing to the clinical setting. Natural teeth still have a role to play in the pre-clinical simulation clinic teaching of postcore techniques.

\section{Conclusions}

Within the limitations of this study, artificial teeth provided an appropriate and realistic simulation compared to extracted natural teeth and were easier to source for the post-core exercises of the preclinical fixed prosthodontics program. More widespread use of artificial teeth was limited by cost.

\section{Abbreviations}

$\%$ - percentage

AS - Australian dollars

3D - three-dimensional

\section{Declarations}

\section{Ethics approval and consent to participate}


Ethics approval was obtained from the Human Research Ethics Committee at The University of Adelaide (H-2020-106).

\section{Consent for publication}

Consent was provided from the participants for the publication of this content

\section{Availability of data and material}

Data is available from the author on request

\section{Competing interests}

The author declares there are no competing interests

\section{Funding}

There are no sources of funding to report

\section{Authors' contributions}

There was a sole author who produced this work

\section{Acknowledgements}

There are no acknowledgements

\section{References}

1. Haralur SB, AI-Malki AE. Student perception about efficacy of preclinical fixed prosthodontic training to facilitate smooth transition to clinical context. J Educ Health Promot. 2014;3:73.

2. Velayo BC, Stark PC, Eisen SE, Kugel G. Using dental students' preclinical performance as an indicator of clinical success. J Dent Educ. 2014;78(6):823-28.

3. Perry S, Bridges S, Burrow MF. A review of the use of simulation in dental education. Simul Healthc. 2015;10(1):31-7.

4. Dudley J. In vitro assessment of simulation teeth in a pre-clinical teaching program. Saud J Oral Sci. 2018;5:75-9.

5. Torabinejad M, Anderson P, Bader J, Brown LJ, Chen LH, Goodacre CJ, et al. Outcomes of root canal treatment and restoration, implant-supported single crowns, fixed partial dentures, and extraction without replacement: a systematic review. J Prosthet Dent. 2007;98:285-311.

6. Dudley J. Implants for the ageing population. Aust Dent J. 2015;60:28-43.

7. Slade GD, Sanders A. Trends in oral health 1987-2006. In: Slade GD, Spencer AJ, Roberts-Thomson KF, editors. Australia's dental generations: the National Survey of Adult Oral Health 2004-06. AlHW 
Cat. no. DEN 165. Canberra: Australian Institute of Health and Welfare (Dental Statistics and Research Series No. 34), 2007:pp. 196-231.

8. Jotkowitz A, Samet N. Rethinking ferrule - a new approach to an old dilemma. Br Dent J. 2010;10(1):25-33. 209(.

9. The glossary of. prosthodontic terms: ninth edition. J Prosthet Dent. 2017;117:e1-105.

10. Goracci C, Ferrari M. Current perspectives on post systems: a literature review. Aust Dent J. 2011;56:77-83.

11. Theodosopoulou JN, Chochlidakis KM. A systematic review of dowel (post) and core materials and systems. J Prosthodont. 2009;18:464-72.

12. Schwartz RS, Robbins JW. Post placement and restoration of endodontically treated teeth: a literature review. J Endod. 2004;30:289-301.

13. Owen TA, Barber M. Direct or indirect post crowns to restore compromised teeth: a review of the literature. Br Dent J. 2018;224(6):413-18.

14. Barfeie A, Thomas MB, Watts A, Rees J. Failure mechanisms of fibre posts: a literature review. Eur J Prosthodont Restor Dent. 2015;23(3):115-27.

15. Al-Thobity AM. Clinical outcomes of zirconium-oxide posts: up-to-date systematic review. Compend Contin Educ Dent. 2016;37(6):e17-20.

16. Figueiredo FED, Martins-Filho PRS, Faria-e-Silva AL. Do metal post-retained restorations result in more root fractures than fiber post-retained restorations? A systematic review and meta-analysis. $J$ Endod. 2015;41(3):309-16.

17. Tran J, Dudley J, Richards L. All-ceramic crown preparations: an alternative technique. Aust Dent J 2017:62(1):65-70.

18. Liu L, Li J, Yuan S, Wang T, Chu F, Lu X, et al. Evaluating the effectiveness of a preclinical practice of tooth preparation using digital training system: A randomised controlled trial. Eur J Dent Educ. 2018;22:e679-86.

19. Jasinevicius TR, Landers $M$, Nelson $S$, Urbankova A. An evaluation of two dental simulation systems: virtual reality versus contemporary non-computer-assisted. J Dent Educ. 2004;68(11):1151-62.

20. Höhne C, Schwarzbauer R, Schmitte M. 3D Printed teeth with enamel and dentin layer for educating dental students in crown preparation. J Dent Educ. 2019;83(12):1457-63.

21. Höhne C, Dickhaut N, Schmitter M. Introduction of a new teaching concept for dentin post preparation with 3D printed teeth. Eur J Dent Educ. 2020. doi:10.1111/eje.12528.

22. Boonsiriphant P, Al-Salihi Z, Holloway JA, Schneider GB. The use of 3D printed tooth preparation to assist in teaching and learning in preclinical fixed prosthodontics courses. $J$ Prosthodont. 2019;28(2):e545-7.

23. Bitter K, Gruner D, Wolf O, Schwendicke F. Artificial versus natural teeth for preclinical endodontic training: a randomized controlled trial. J Endod. 2016;42(8):1212-7. 
24. Taylor TD, Aquilino SA, Jordan RD. Prosthodontic laboratory and curriculum survey. Part IV: fixed prosthodontic curriculum survey. J Prosthet Dent. 1985;53(2):267-70.

25. Petropoulos VC, Weintraub A, Weintraub GS. Predoctoral fixed prosthodontics curriculum survey. J Prosthodont. 1998;7:183-91.

26. Chang BM, Munoz DM, Donoff RB, Kinnunen T, Wright RF. A 10-year survey of US deans: trends, challenges, and mentoring in prosthodontics. Part 2. J Prosthodont. 2012;21(1):65-72.

27. Hey J, Stimmelmayr M, Hirsch C, Beuer F. Content and goals of preclinical prosthodontic programs at german-language dental schools. J Prosthodont. 2014;23(3):246-51.

28. Nimmo A, Woolsey GD, Arbree NS, Saporito R, Cooney JP. Defining predoctoral prosthodontic curriculum: a workshop sponsored by the American College of Prosthodontists and the prosthodontic forum. J Prosthodont. 1998;7:30-4.

29. Sampaio-Fernandes M, Rodrigues MDS, Oliveira SJ, Reis-Campos JC, de Azevedo ÁAF, Figueiral MH. Students' self-confidence and perceived quality of prosthodontics education: a study in the Faculty of Dental Medicine of the University of Porto. Eur J Dent Educ. 2020. doi:10.1111/eje.12537.

30. Barrero C, Duqum I, Petrola F. Dental students' perceived preparedness to treat patients in clinic after a fixed prosthodontics course: survey results of a case study. J Dent Educ. 2015;79(4):409-16.

31. Cardoso JA, Barbosa C, Fernandes S, Silva CL, Pinho A. Reducing subjectivity in the evaluation of pre-clinical dental preparations for fixed prosthodontics using the Kavo PrepAssistant ${ }^{\circledR}$. Eur J Dent Educ. 2006;10:149-56.

32. Tran J, Dudley J, Richards L. All-ceramic crown preparations: An alternative technique. Aust Dent J. 2017;62(1):65-70.

33. Haralur S, Al-Malkil A. Student perception about efficacy of preclinical fixed prosthodontic training to facilitate smooth transition to clinical context. J Educ Health Promot. 2014;3:73.

34. Qualtrough AJ. Undergraduate endodontic education: what are the challenges? Br Dent J. 2014;216:361-4.

35. Reymus M, Fotiadou C, Kessler A, Heck K, Hickel R, Diegritz C. 3D printed replicas for endodontic education. Int Endod J 2019:52:123-30.

36. Nissin dental products. Anatomical pulp cavity and root model. 2019. https://www.nissindental.net/products/DentalTrainingProducts/Parts/B22X_Series/index.html.

37. Garcia PP, Wambier LM, de Geus JL, da Cunha LF, Correr GM, Gonzaga CC. Do anterior and posterior teeth treated with post-and-core restorations have similar failure rates? A systematic review and meta-analysis. J Prosthet Dent. 2019;121(6):887-94.

38. Gómez-Polo M, Llidó B, Rivero A, Del Río J, Celemín A. A 10-year retrospective study of the survival rate of teeth restored with metal prefabricated posts versus cast metal posts and cores. J Dent. 2010;38:916-20.

39. Figueiredo FE, Martins-Filho PR, Faria-E-Silva AL. Do metal post-retained restorations result in more root fractures than fiber post-retained restorations? A systematic review and meta-analysis. J Endod. 
2015;41(3):309-16.

40. Soares CJ, Valdivia AD, da Silva GR, Santana FR, Menezes Mde S. Longitudinal clinical evaluation of post systems: a literature review. Braz Dent J. 2012;23:135-40.

41. Montero J, Dib A, Guadilla Y, Flores J, Santos JA, Aguilar RA, Gómez-Polo C. Dental students' perceived clinical competence in prosthodontics: comparison of traditional and problem-based learning methodologies. J Dent Educ. 2018;82(2):152-62.

42. Dudley J. Comparison of coronal tooth reductions resulting from different crown preparations. Int J Prosthodont. 2018;31(2):142-44.

\section{Tables}

Due to technical limitations, table 1 is only available as a download in the Supplemental Files section.

\section{Figures}

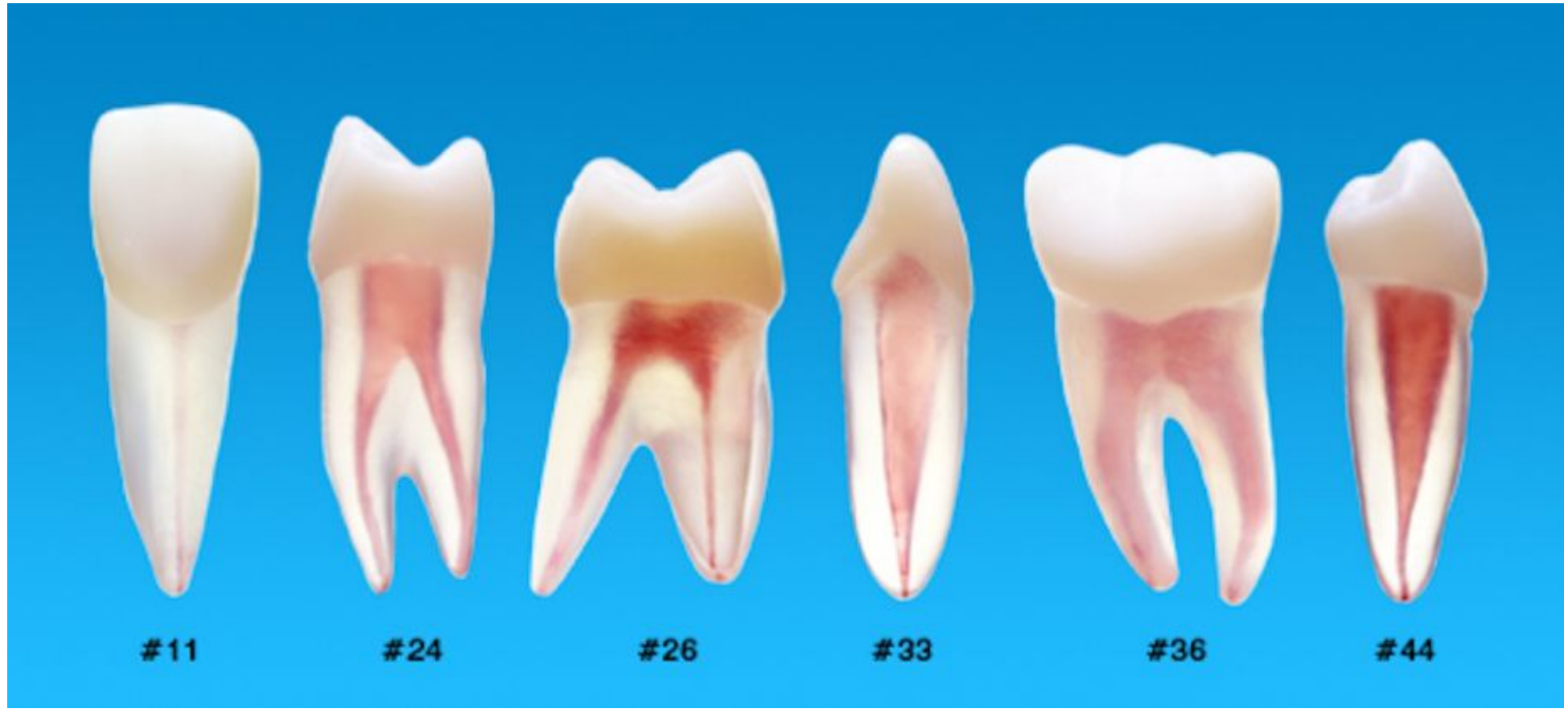

\section{Figure 1}

Artificial tooth - Nissin Anatomical Pulp Cavity \& Root Model [B22X Series] (sourced from: https://www.nissin-dental.net/products/DentalTrainingProducts/Parts/B22X_Series/index.html) 


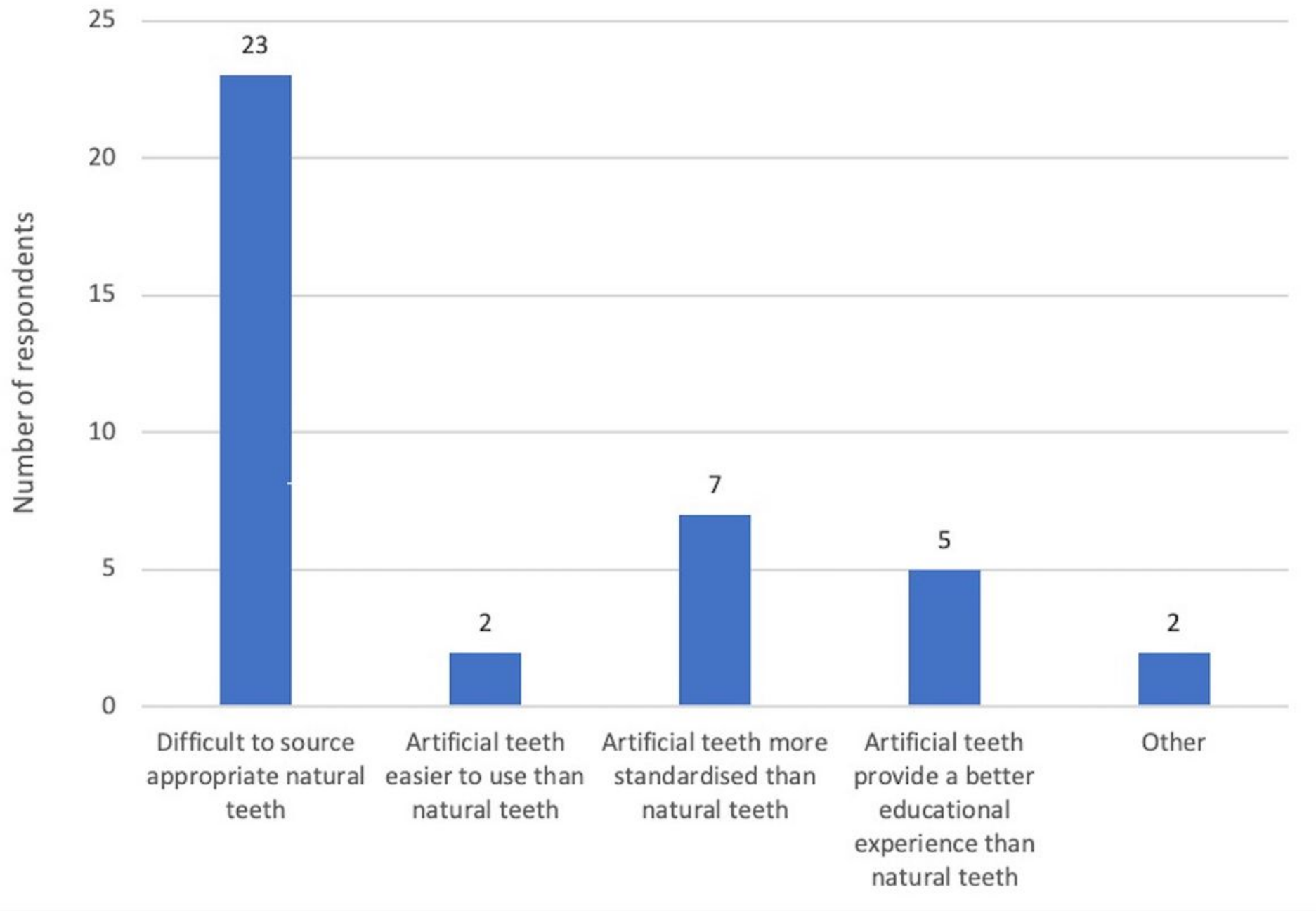

Figure 2

Reasons for choosing artificial teeth (multiple answers permitted) $(n=25,39$ responses) 


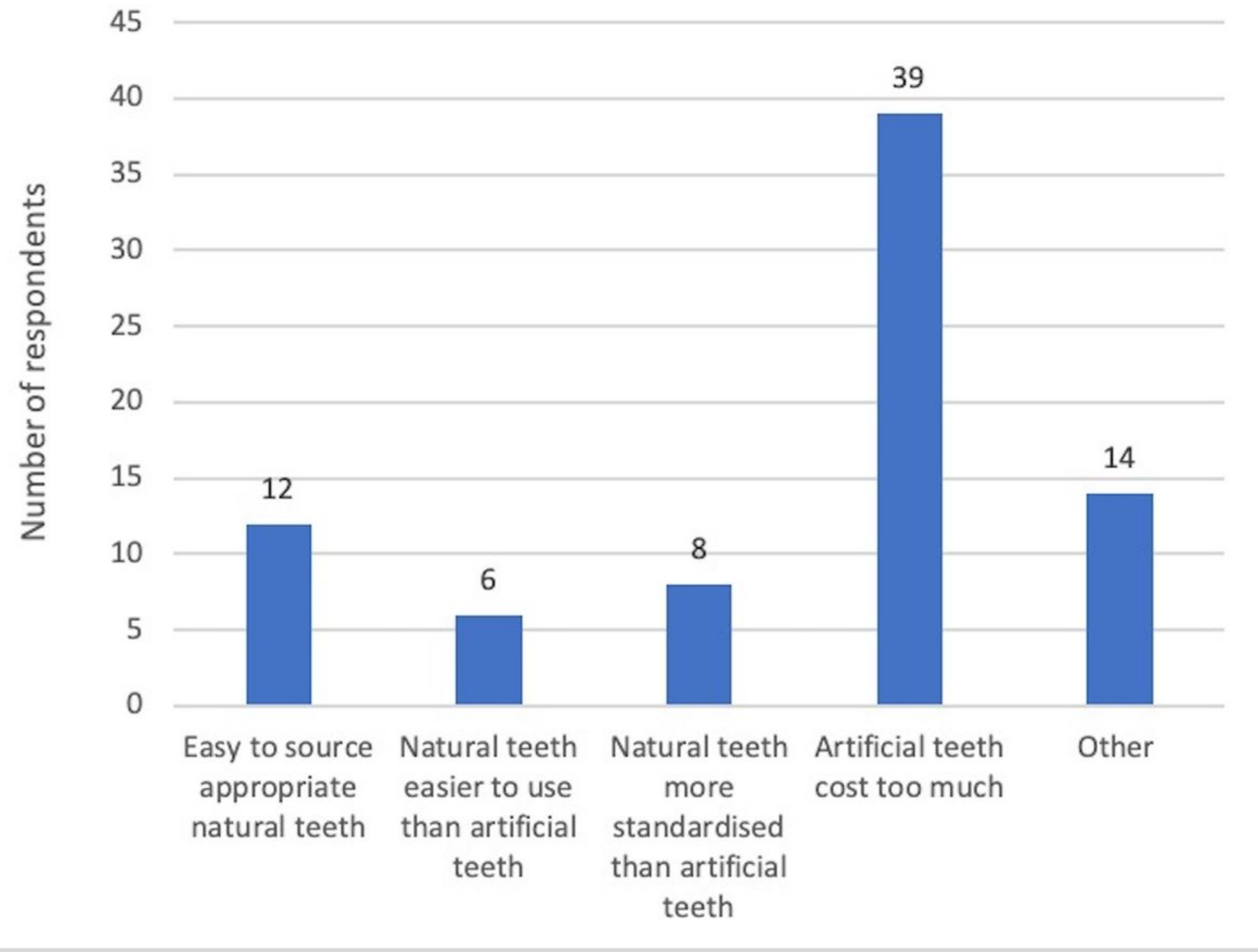

Figure 3

Reasons for choosing natural teeth (multiple answers permitted) ( $n=45,79$ responses) 


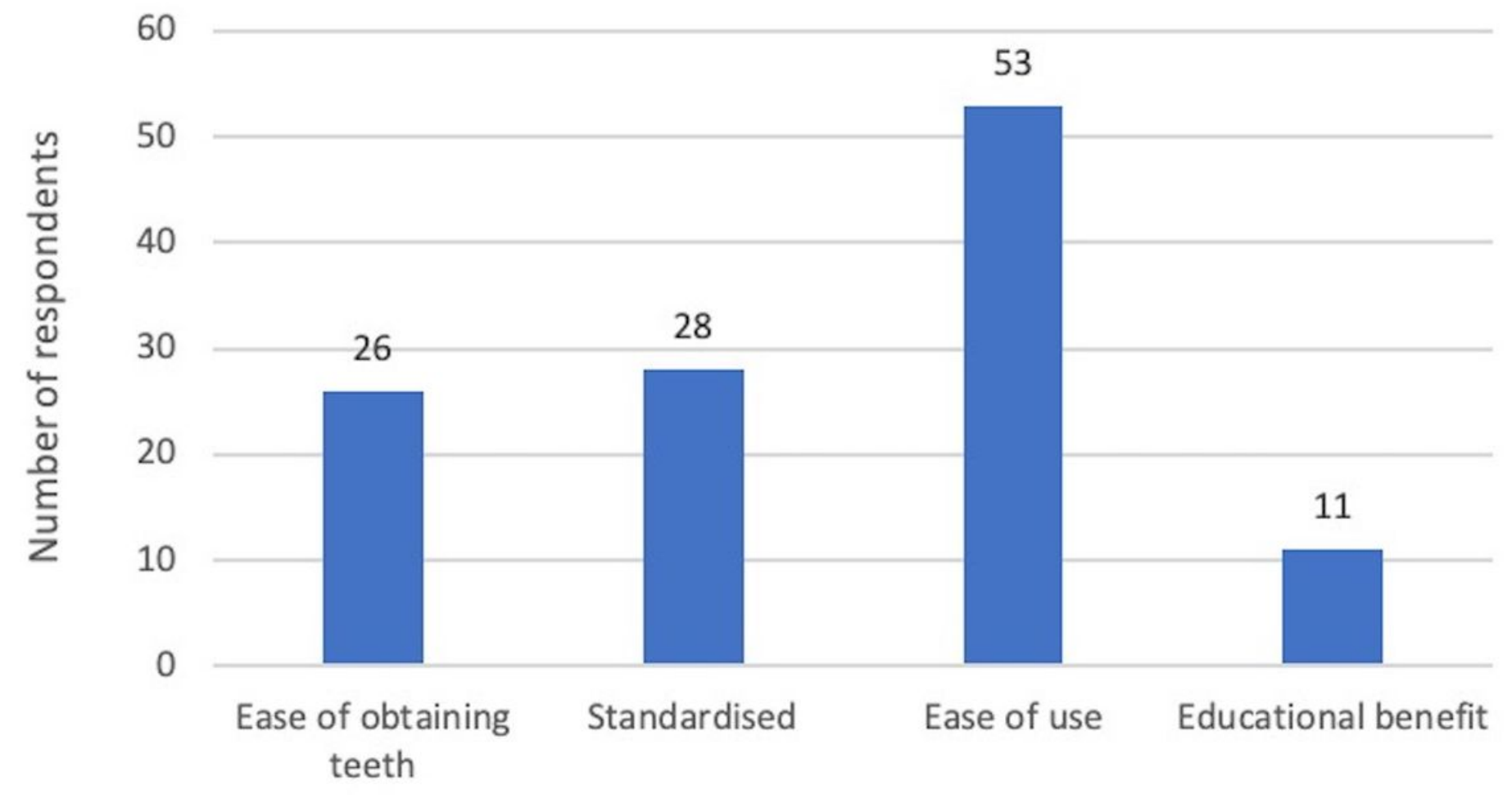

Figure 4

artificial teeth were used in the future, positive reasons for selecting artificial teeth (multiple answers permitted) ( $n=45,118$ responses) 


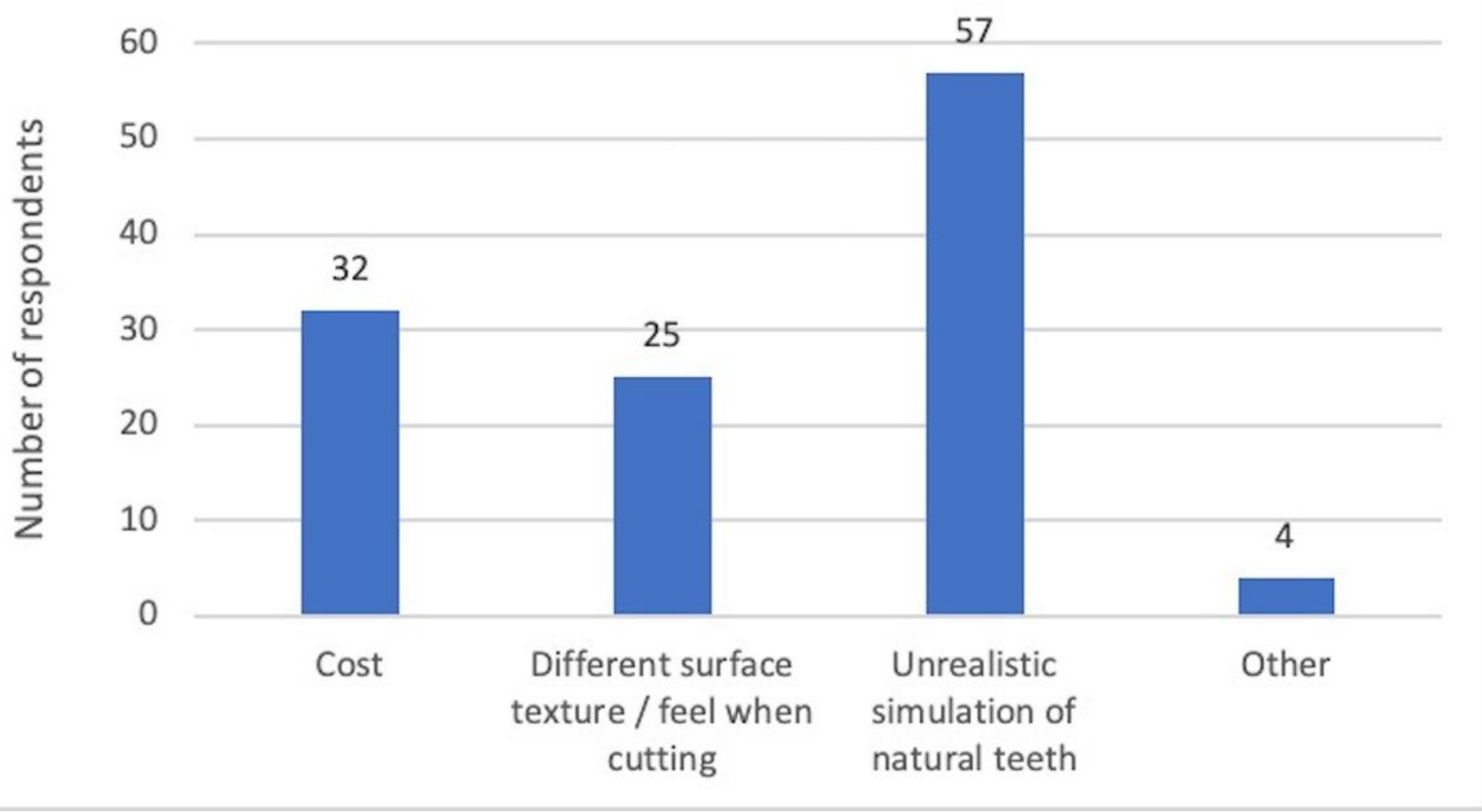

Figure 5

If artificial teeth were used in the future, negative reasons for selecting artificial teeth (multiple answers permitted) ( $n=45,118$ responses)

\section{Supplementary Files}

This is a list of supplementary files associated with this preprint. Click to download.

- Table1.pdf 